\title{
SNP Markers Reveal Relationships between Fruit Paternity, Fruit Quality and Distance from a Cross- pollen Source in Persea Americana Orchards
}

\section{Wiebke Kämper ( $\nabla$ w.kaemper@griffith.edu.au )}

Griffith University

\section{Steven Ogbourne}

University of the Sunshine Coast

\section{David Hawkes}

Australian Genome Research Facility

\section{Stephen Trueman}

Griffith University

\section{Research Article}

Keywords: avocado, fatty acid, fruit quality, nutrients, outcrossing, paternity, pollen movement

Posted Date: December 14th, 2020

DOl: https://doi.org/10.21203/rs.3.rs-123913/v1

License: (9) This work is licensed under a Creative Commons Attribution 4.0 International License. Read Full License 


\section{Abstract}

Plant reproductive output is increasingly pollen limited, and cross-pollination can improve fruit yield, fruit size and nutritional quality of many food crops. However, we rarely understand what proportions of the crop result from self- or cross-pollination, how cross-pollination affects crop quality, and how far pollen is transported by pollinators. Management strategies to improve pollination services are consequently not optimal for many crops.

We utilised a series of SNP markers, unique for each cultivar of avocado, to quantify proportions of selfand cross-paternity in fruit of Hass avocado at increasing distances from cross-pollen sources. We assessed whether distance from a cross-pollen source determined the proportions of self-pollinated and cross-pollinated fruit, and evaluated how self- and cross-paternity affected fruit size and nutritional quality.

Avocado fruit production resulted from both self- and cross-pollination. Cross-pollination levels decreased with increasing distance from a cross-pollen source, from $63 \%$ in the row adjacent to another cultivar to $25 \%$ in the middle of a single-cultivar block, suggesting that pollen transport was limited across orchard rows. Limited pollen transport did not affect fruit size or quality in Hass avocados as xenia effects of a Shepard polliniser on size and nutritional quality were minor.

\section{Introduction}

Pollination is essential for plant reproduction in both natural and agricultural ecosystems ${ }^{1-3}$. However, plant reproduction is increasingly limited by the quality or quantity of pollen deposited on the stigmas of flowers ${ }^{4,5}$. Roughly $50 \%$ of plant species rely on or benefit from cross-pollination for successful reproduction ${ }^{6,7}$. Cross-pollination occurs when pollen from one genotype is transferred to the stigma of another genotype, whereas self-pollination occurs when pollen is transferred within the same genotype ${ }^{8}$. Self-incompatible plants require cross-pollination to reproduce sexually, and some self-compatible plants have increased fruit set when cross-pollinated ${ }^{9-11}$. The type of pollen deposited on the stigma can, thus, be important for successful reproduction ${ }^{12-14}$.

Tree crop orchards are often established with only a few clonally-propagated cultivars. Each cultivar has one genotype, making trees of a single cultivar a clone ${ }^{8,15}$. Cross-pollination occurs when a stigma of one cultivar receives pollen from flowers of another cultivar whereas self-pollination occurs when pollen of the same cultivar is transferred ${ }^{8}$. Cross-pollination increases fruit size, quality and shelf life in many crops, including some tree nuts and berries ${ }^{14,16-18}$. Increased nutritional quality of the fruit can provide health benefits for consumers; e.g. cross-pollination in almonds increases the oleic to linoleic acid ratio, which has been linked to their cardio-protective effects ${ }^{17,19}$. For most crops, we do not understand to what extent self- $v$. cross-pollination contribute to the crop at harvest despite plant reproduction being increasingly pollen limited ${ }^{4,5}$. We also do not know how self- $v$. cross-pollination affect crop quality parameters such as fruit size or nutritional quality. 
Avocado (Persea americana, Lauraceae) is a subtropical evergreen tree native to Mexico and Central America. Worldwide, the avocado industry relies on approximately 12 cultivars, but with approximately $90 \%$ of production relying on a single cultivar, $\mathrm{Hass}^{20}$. Demand for avocado is increasing exponentially, partly due to health benefits associated with avocado consumption ${ }^{21,22}$. Avocado fruit are rich in monounsaturated fatty acids such as oleic acid and palmitoleic acid ( 70\%), dietary fibre, vitamins $\mathrm{K}$ and $\mathrm{E}$, and the mineral nutrients, potassium and magnesium ${ }^{21-23}$. Consumption of avocado fruit has been linked to improved blood lipid profiles, with lower LDL-cholesterol, lower triglycerides and higher HDL-cholesterol, that are linked to reduced cardiovascular risk $22,24-26$.

Distances between trees of different cultivars in horticultural orchards, including avocado, are often large because single cultivars are planted in wide blocks. This type of planting design can simplify farm management practices ${ }^{27}$. However, planting trees in wide single-cultivar blocks poses a challenge for ensuring cross-pollination. Pollinators must travel long distances across the orchard to transfer pollen between cultivars if distances between the cultivars are large. Cross-pollination is facilitated in crops such as avocado by protogyny, where each flower is functionally female initially and, later, functionally male ${ }^{28}$. Avocado flowers either open as female on the morning of the first day, close in the late morning, and then open as male on the afternoon of the following day (type A), or open as female on the afternoon of the first day, close in the late afternoon, and then open as male the following morning (type B). Avocado orchards are typically established with at least one type A cultivar such as Hass and one type B cultivar such as Shepard to ensure that pollen is available during the female stage of flowers ${ }^{29}$. Flies and bees, not wind, are the main pollen vectors in avocado orchards ${ }^{30,31}$.

Self-pollination and cross-pollination both occur in avocado ${ }^{32-34}$ and variable outcrossing rates between $31 \%$ and $83 \%$ have been reported for Hass ${ }^{32,33,35}$. Few studies have assessed the effect of distance from a cross-pollen source on the prevalence of self- $v$. cross-paternity, and very few studies have compared the quality of fruit that resulted from self- $v$. cross-pollination. Consumer desirability might differ between self- and cross-pollinated fruit if the fruit differ in size and nutritional quality. Self-pollinated Fuerte avocado fruit have lower fruit, seed and pericarp mass than cross-pollinated fruit, but similar fruit:seed ratio to cross-pollinated fruit ${ }^{36}$. To our knowledge, no study has investigated the comparative nutritional quality of self- $v$. cross-pollinated avocado fruit.

We aimed to assess the contributions of self- and cross-pollination to fruit production in avocado orchards. We expected pollen to be transported over short distances. We hypothesised that there would be a greater proportion of self-pollinated fruits with increasing distance from a cross-pollen source and that self-pollination would decrease fruit size and quality. We aimed to determine how far cross-pollen was effectively transferred across orchard rows. We aimed to quantify whether the proportions of selfand cross-pollinated fruit, fruit size (including fruit mass, flesh mass and seed mass) and seed proportion, varied at different distances from a cross-pollen source. We also aimed to identify how selfand cross-pollination affected fruit size, seed proportion, mineral nutrient concentrations and fatty acid composition of avocado fruit flesh. 


\section{Results}

\section{Paternity and fruit size at different distances from a cross- pollen source}

A total of $52.4 \%$ of fruit $(N=190)$ resulted from self-pollination and $47.6 \%$ resulted from cross-pollination. Almost all the cross-pollinated fruit (95\%; 86 of 91 fruit) were pollinated by cultivar Shepard. The remaining five cross-pollinated fruit were pollinated by Lamb Hass (1 fruit) or Sharwil (1 fruit) or the cross-pollen parent could not be assigned definitively ( 3 fruit). The percentage of self-pollinated fruit increased with increasing distance (i.e. the number of rows) from a cross-pollen source, from $37-75 \%$, whereas the percentage of cross-pollinated fruit decreased from $63-25 \%$ (Fig. $1 ; F=4.00, P=0.02$ ). The percentage of cross-pollinated fruit declined significantly by 11 rows from a cross-pollen source (Fig. 1). Distance from a cross-pollen source did not affect fruit mass $(F=0.39, p=0.76)$, flesh mass $(F=0.60, p=$ $0.62)$, seed mass $(F=0.72, p=0.55)$ or seed proportion $(F=2.48, p=0.09)$ (Table 1$)$.

Table 1

Fruit size of avocado cultivar Hass fruit collected at different distances from a cross-pollen source

\begin{tabular}{|lllll|}
\hline Fruit size & Row 1 & Row 2 & Row 3 & Row 11/12/14 \\
\hline Total fresh mass $(\mathrm{g})$ & $193.19 \pm 11.98$ & $190.84 \pm 13.58$ & $207.61 \pm 2.78$ & $201.90 \pm 15.60$ \\
\hline Flesh mass $(\mathrm{g})$ & $153.71 \pm 8.81$ & $159.75 \pm 13.32$ & $168.11 \pm 2.44$ & $166.70 \pm 14.35$ \\
\hline Seed mass $(\mathrm{g})$ & $39.48 \pm 3.34$ & $34.88 \pm 3.51$ & $39.50 \pm 2.43$ & $36.64 \pm 2.34$ \\
\hline Seed proportion & $20.36 \pm 0.68$ & $18.72 \pm 0.68$ & $18.90 \pm 1.08$ & $18.35 \pm 0.68$ \\
\hline Means \pm SE within each parameter do not differ significantly (mixed model; P > 0.05; $\mathrm{n}=32$ trees) \\
\hline
\end{tabular}

\section{Effect of pollen parentage on fruit size, mineral nutrient concentrations and fatty acid composition}

Hass avocado fruit that were self-pollinated by Hass or cross-pollinated by Shepard did not differ significantly in fruit mass, flesh mass, seed mass or seed proportion (Table 2). Self-pollinated fruit had 9.1\% lower calcium and $10.6 \%$ higher phosphorus concentrations than cross-pollinated fruit (Table 3 ). Self- and cross-pollinated fruit did not differ in the concentrations of other elements (Table 3). Selfpollinated fruit had a $2.8 \%$ higher ratio of unsaturated to saturated fatty acids (UFA:SFA) than crosspollinated fruit (Table 4). Self- and cross-pollinated fruit did not differ significantly in the relative contributions of palmitic, palmitoleic, stearic, oleic, elaidic or linoleic acid to the total fatty acid composition (Table 4). 
Table 2

Fruit size of avocado cultivar Hass fruit pollinated by self-pollen (Hass) or cross-pollen (Shepard)

\begin{tabular}{|c|c|c|c|c|c|c|}
\hline \multirow[t]{3}{*}{ Fruit size } & \multicolumn{6}{|c|}{ Pollen parent } \\
\hline & \multicolumn{3}{|c|}{ Hass (self-pollinated) } & \multicolumn{3}{|c|}{ Shepard (cross-pollinated) } \\
\hline & \multicolumn{3}{|l|}{$N=99$} & \multicolumn{3}{|l|}{$N=86$} \\
\hline Total fresh mass (g) & 195.54 & \pm & 5.98 & 197.83 & \pm & 8.26 \\
\hline Flesh mass (g) & 155.79 & \pm & 4.60 & 160.97 & \pm & 6.72 \\
\hline Seed mass (g) & 37.24 & \pm & 1.45 & 37.04 & \pm & 1.91 \\
\hline Seed proportion & 0.19 & \pm & 0.01 & 0.19 & \pm & 0.01 \\
\hline Means \pm SE do not di & er signific & & nixed $r$ & odel; P > & & trees) \\
\hline
\end{tabular}


Table 3

Nutrient concentrations in the flesh of avocado cultivar Hass fruit pollinated by self-pollen (Hass) or cross-pollen (Shepard)

\begin{tabular}{|c|c|c|c|c|c|c|c|c|}
\hline \multirow[t]{3}{*}{ Nutrient } & \multicolumn{8}{|c|}{ Pollen parent } \\
\hline & \multicolumn{4}{|c|}{ Hass (self-pollinated) } & \multicolumn{4}{|c|}{ Shepard (cross-pollinated) } \\
\hline & $N=95$ & & & & $N=83$ & & & \\
\hline C (\%) & 15.95 & \pm & 0.26 & & 15.72 & \pm & 0.30 & \\
\hline $\mathrm{N}(\%)$ & 0.20 & \pm & 0.01 & & 0.17 & \pm & 0.01 & \\
\hline $\mathrm{Al}(\mathrm{mg} / \mathrm{kg})$ & 4.08 & \pm & 0.94 & & 3.90 & \pm & 0.98 & \\
\hline B (mg/kg) & 32.45 & \pm & 2.15 & & 34.11 & \pm & 3.16 & \\
\hline $\mathrm{Ca}(\mathrm{mg} / \mathrm{kg})$ & 131.79 & \pm & 9.52 & $b$ & 144.94 & \pm & 11.44 & a \\
\hline $\mathrm{Cu}(\mathrm{mg} / \mathrm{kg})$ & 3.48 & \pm & 0.21 & & 3.29 & \pm & 0.21 & \\
\hline $\mathrm{Fe}(\mathrm{mg} / \mathrm{kg})$ & 10.32 & \pm & 0.66 & & 9.84 & \pm & 0.95 & \\
\hline $\mathrm{K}(\mathrm{mg} / \mathrm{kg})$ & 4929.11 & \pm & 185.63 & & 4719.23 & \pm & 227.76 & \\
\hline $\mathrm{Mg}(\mathrm{mg} / \mathrm{kg})$ & 277.58 & \pm & 9.27 & & 281.61 & \pm & 12.66 & \\
\hline $\mathrm{Mn}(\mathrm{mg} / \mathrm{kg})$ & 2.37 & \pm & 0.11 & & 2.53 & \pm & 0.16 & \\
\hline $\mathrm{Na}(\mathrm{mg} / \mathrm{kg})$ & 152.01 & \pm & 9.50 & & 151.16 & \pm & 7.78 & \\
\hline$P(\mathrm{mg} / \mathrm{kg})$ & 515.61 & \pm & 18.64 & a & 461.16 & \pm & 20.09 & $b$ \\
\hline $\mathrm{S}(\mathrm{mg} / \mathrm{kg})$ & 320.13 & \pm & 16.31 & & 297.22 & \pm & 19.41 & \\
\hline Zn (mg/kg) & 10.03 & \pm & 0.56 & & 9.20 & \pm & 0.78 & \\
\hline
\end{tabular}


Table 4

Relative abundances of fatty acids (mean \pm SE) in the flesh of avocado cultivar Hass fruit pollinated by self-pollen (Hass) or cross-pollen (Shepard)

\begin{tabular}{|c|c|c|c|c|c|c|c|c|}
\hline \multirow[t]{3}{*}{ Fatty acid } & \multicolumn{8}{|c|}{ Pollen parent } \\
\hline & \multicolumn{4}{|c|}{ Hass (self-pollinated) } & \multicolumn{4}{|c|}{ Shepard (cross-pollinated) } \\
\hline & $N=96$ & & & & $N=83$ & & & \\
\hline Palmitic - C16:0 (\%) & 7.09 & \pm & 0.10 & & 7.10 & \pm & 0.11 & \\
\hline Palmitoleic - C16:1 cis (\%) & 9.38 & \pm & 0.37 & & 9.42 & \pm & 0.39 & \\
\hline Stearic - C18:0 (\%) & 40.10 & \pm & 0.38 & & 39.23 & \pm & 0.37 & \\
\hline Oleic - C18:1 cis (\%) & 31.47 & \pm & 0.54 & & 31.99 & \pm & 0.48 & \\
\hline Elaidic - C18:1 trans (\%) & 11.59 & \pm & 0.23 & & 11.88 & \pm & 0.27 & \\
\hline Linoleic - C18:2 (\%) & 0.36 & \pm & 0.01 & & 0.38 & \pm & 0.02 & \\
\hline Saturated fatty acids (SFA) & 68.17 & \pm & 0.53 & & 67.63 & \pm & 0.48 & \\
\hline Unsaturated fatty acids (UFA) & 31.83 & \pm & 0.53 & & 32.37 & \pm & 0.48 & \\
\hline UFA:SFA & 2.18 & \pm & 0.05 & a & 2.12 & \pm & 0.05 & $b$ \\
\hline
\end{tabular}

\section{Discussion}

Self- and cross-paternity were both common among Hass avocado fruit in our study, but the percentage of cross-pollinated fruit decreased with increasing distance from a cross-pollen source. Self- and crosspollinated fruit did not differ significantly in fruit size and they differed little in their nutritional composition. However, self-pollinated fruit had lower calcium concentrations, higher phosphorus concentrations and a slightly elevated UFA:SFA ratio. These results demonstrate that pollen flow is limited across avocado orchards, but that xenia effects of a Shepard polliniser on the size and nutritional quality of Hass fruit quality are minor.

Hass avocado fruit resulted from either self-pollination or cross-pollination, demonstrating some degree of self-compatibility in avocado flowers. Between $25 \%$ and $63 \%$ of fruit were cross-pollinated, with the frequency of outcrossing being dependent on the proximity to flowers of another cultivar. The $25 \%$ of fruit that were cross-pollinated in the middle of a Hass block had received pollen that was transported at least 130-147 m, even though self-pollen was potentially available from all trees planted at a closer distance. The orchards in our study were established with Hass, Lamb Hass and Wurtz as type A cultivars and Shepard as the type B cultivar, ensuring that Shepard pollen was available during the female stage of the Hass, Lamb Hass and Wurtz trees. Protogyny can explain why $25 \%$ of fruit were cross-pollinated in the 
middle of the single-cultivar Hass block because only cross pollen was widely released during the female stage of Hass flowers. The temporal separation between male and female flowers in the flowering types is not complete and can be affected by temperature ${ }^{37}$. Other mechanisms such as selective fruitlet abscission might also have occurred ${ }^{33,38}$. Self-pollinated avocado fruitlets can be more prone to selective abortion, leading to an over-representation of cross-pollinated fruit at harvest ${ }^{38}$. However, younger fruitlets resulting from pollination late in flowering are also more prone to selective abortion ${ }^{33}$.

A decrease in the percentage of cross-pollinated Hass fruit with increasing distance from a cross-pollen source has been reported previously ${ }^{33,39}$. Our results showed a significant decrease in the percentage of cross-pollinated fruit when comparing the middle of a single-cultivar block to the row adjacent to a crosspollen source, but not when comparing 2 or 3 rows from the cross-pollen source to the row adjacent to the cross-pollen source. Other studies have reported a decrease in the percentage of cross-pollinated fruit at smaller distances from a cross-pollen source than we found; e.g. from 0-28 $\mathrm{m}$ or from 0-92 $\mathrm{m}$ compared with from $0-130 \mathrm{~m}$ in our study ${ }^{33,39}$. The high percentages of cross-pollinated fruit at 2 or 3 rows from a cross-pollen source in our study may suggest that Shepard pollen is moved further across orchard rows or it may suggest differences in pollinator movements compared with other studies ${ }^{40-42}$.

Self- and cross-pollinated fruit did not differ in fruit mass, flesh mass, seed mass or seed proportion.

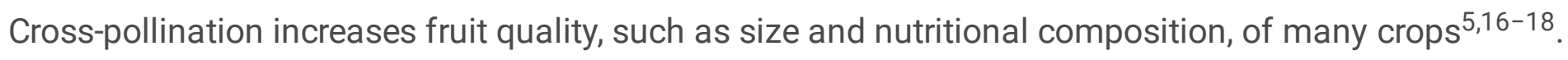
The effect of different pollen parents on characteristics of the fruit is a phenomenon termed xenia ${ }^{43}$. Fruit mass and seed mass of Fuerte avocado fruit cross-pollinated by Tops-Tops, Teague or Ettinger are higher than of self-pollinated fruit ${ }^{38}$. Likewise, seed mass of Hass fruit cross-pollinated by Ettinger is greater than that of self-pollinated fruit ${ }^{44}$. Potentially, pollination by Ettinger results in larger Hass fruit than does pollination by Shepard.

Nutrient levels and fatty acid composition differed little between self- and cross-pollinated Hass fruit. However, self-pollinated fruit a higher UFA:SFA ratio than cross-pollinated fruit. To our knowledge, no studies have investigated the nutritional quality of self- and cross-pollinated avocado fruit. The slightly higher UFA:SFA ratio of self-pollinated fruit could be beneficial for human health because a diet rich in unsaturated fatty acids decreases LDL-cholesterol levels and other cardiovascular risk factors $22,26,45$. However, the UFA:SFA ratio in avocado is highly variable and the ratio in our study was relatively low at 2.18 and 2.12 in self- and cross-pollinated fruit, respectively 22,46 . The consumption of fruit from cooler growing regions that have higher UFA:SFA ratios will have a much greater effect on health than the small observed difference between self- and cross-pollinated fruit in our study ${ }^{46}$. Self-pollinated fruit had lower calcium and higher phosphorus levels than cross-pollinated fruit. Phosphorus, unlike other micronutrients such as calcium, iron, iodine, magnesium and zinc, whose dietary intakes are often inadequate, is almost never in short supply in the human diet ${ }^{47}$. The calcium nutrient levels of cross-pollinated fruit might be more beneficial for human health. 
Self- and cross-pollination both contributed to the harvested avocado crop. The percentage of crosspollinated fruit decreased with increasing distance from a cross-pollen source, indicating limited crosspollen movement to the middle of single-cultivar blocks. Xenia effects of a Shepard polliniser were minimal, because fruit size, the levels of most mineral nutrients, and the contributions of most fatty acids to total fatty acid composition did not differ significantly between self- and cross-pollinated fruit. However, further research should be undertaken to determine whether cross-pollination affects initial fruit set, fruitlet retention and, thus, overall tree yield.

\section{Material And Methods}

\section{Study sites and design}

Hass avocado fruit were harvested from two commercial orchards near Childers, Queensland, Australia ( $25^{\circ} 08^{\prime} 17^{\prime \prime S} 152^{\circ} 22^{\prime} 40^{\prime \prime} \mathrm{E}$ and $\left.25^{\circ} 13^{\prime} 32^{\prime \prime S} 152^{\circ} 17^{\prime} 53^{\prime \prime} \mathrm{E}\right)$. The soil at both orchards was red clay-loam. The average maximum daily temperature during the study (April and May 2018) was $27.2^{\circ} \mathrm{C}$, the average minimum daily temperature was $16.3^{\circ} \mathrm{C}$ and the total rainfall was $36 \mathrm{~mm}$ (Bureau of Meteorology, Bundaberg, 2020). Orchard 1 contained blocks of Hass and Shepard that were 26 rows wide, with trees being 13 years old. Tree spacing was 10-11 $\mathrm{m}$ between rows and $5 \mathrm{~m}$ within a row. The distance to the next block containing trees of the other cultivar was 15-20 m because blocks of different cultivars were separated by roads. Orchard 2 contained blocks of Hass, Shepard, Lamb Hass and Wurtz that were 6-22 rows wide, with trees being 18-21 years old. Tree spacing was $10 \mathrm{~m}$ between rows and $5 \mathrm{~m}$ within a row. The distance to the next block containing trees of a different cultivar was $10 \mathrm{~m}$.

A total of 320 mature Hass fruit was collected from 32 trees from two transects in orchard 1 and six transects in orchard 2. Each transect consisted of individual trees at four sampling points: (i) 1, (ii) 2, (iii) 3 and (iv) 11-14 rows from the cross-pollen source. The last sampling point was chosen to represent the middle of the block, and thus depended on the width of the single-cultivar block. Ten fruit were collected in a stratified design from each tree, with each tree divided into five sectors on the side of the tree that faced the neighbouring cultivar ${ }^{42}$. Two fruit were sampled per sector, one from the inside and one from the outside of the canopy, on either 18 April or 9/10 May 2018, depending on the orchard. Six fruit per tree were selected randomly for further analyses, resulting in 192 samples (48 samples per sampling point at $1,2,3$ and 11-14 rows from the cross-pollen source). Fruit were kept in the shade until moved to a cold room at $4{ }^{\circ} \mathrm{C}$ within 20 hours of collection ${ }^{48,49}$.

Fruit were stored at $4{ }^{\circ} \mathrm{C}$ for 10 or $20 \mathrm{~d}$, before being moved to room temperature $\left(21^{\circ} \mathrm{C}\right)$ to allow onset of ripening. Fruit were ripe after $10.6 \pm 1.0$ days (mean $\pm \mathrm{SE}$ ) at room temperature. Ripeness was confirmed by measuring skin and flesh firmness with a handheld sclerometer $(8 \mathrm{~mm}$ head; Lutron Electronic Model: FR-5120, Coopersburg, PA). Fruit were considered ripe when the maximum force required to impress the sclerometer tip $1 \mathrm{~mm}$ deep was $<15 \mathrm{~N}$ for the skin and $<5 \mathrm{~N}$ for the flesh ${ }^{50,51}$. Flesh firmness was measured after removing small patches of skin at two locations along the equator of the fruit, with the two measurements taken at $90^{\circ}$ from each other. Fruit and seed fresh mass were recorded. Subsamples 
of flesh were then taken to measure the: (i) relative contribution of six fatty acids to the total fatty acid composition; (ii) ratios of saturated and unsaturated fatty acids; and (iii) concentrations of mineral nutrients. A $50 \mathrm{mg}$ subsample of the seed was also taken for genotyping.

\section{Mineral nutrients}

We determined the concentrations of 14 nutrients from flesh taken from two locations, near the apex and along the equator of each fruit. We used combustion analysis (TruSpec ${ }^{\circ}$, LECO Corporation, St. Joseph, $\mathrm{MI}$ ) for nitrogen (N) and carbon (C) and inductively coupled plasma-atomic emission spectroscopy (Vista Pro ${ }^{B}$, Varian Incorporation, Palo Alto, CA) after nitric and perchloric acid digestion for sulphur (S), phosphorus $(\mathrm{P})$, potassium $(\mathrm{K})$, aluminium $(\mathrm{Al})$, boron $(\mathrm{B})$, calcium $(\mathrm{Ca})$, copper $(\mathrm{Cu})$, iron (Fe), magnesium $(\mathrm{Mg})$, manganese $(\mathrm{Mn})$, sodium $(\mathrm{Na})$ and zinc $(\mathrm{Zn})^{52-55}$.

\section{Fatty acids}

Approximately $40 \mathrm{~g}$ of flesh was taken from each fruit and oil was extracted using a modification of the protocol of Bai et al. ${ }^{56}$. The flesh was mashed finely before being stirred for 15 min in the presence of $30 \mathrm{~mL}$ of pentane. Fatty acid composition was determined by gas chromatography-mass spectrometry. Peak areas were used to calculate the relative proportions of each fatty acid. Fatty acids that consistently accounted for $<0.3 \%$ of the composition were excluded.

\section{MassARRAY design}

DNA extraction followed the glass-fibre plate DNA extraction protocol for plants (http://ccdb.ca/resources/) ${ }^{57}$. We used disposable $2.3 \mathrm{~mm}$ and $0.1 \mathrm{~mm}$ zirconia/silica beads prior to shaking on a TissueLyser II (Qiagen, Hilden, Germany). A ddRADseq approach was used to screen 42 samples from 10 avocado cultivars for private alleles: Carmen Hass (leaf samples of 5 individual trees), Fuerte (4), Hass (5), Lamb Hass (5), Maluma Hass (5), Reed (4), Sharwil (3), Shepard (5), Velwick (1), and Wurtz (5) ${ }^{58,59}$. The highly-similar cultivars Hass and Carmen Hass produced no private alleles, and so the analysis was performed treating Hass and Carmen Hass as a single group.

Double-digest RADseq is commonly performed using 75 bp reads. We opted for longer reads (150 bp) to support downstream assay development for MassARRAY genotyping assays. Sequences extracted for private alleles from each cultivar were imported into Agena Assay Designer software (AgenaCX). All proximal variants identified by Stacks were annotated onto the sequences, and preference was given to sequences with low degrees of variation. Standard design parameters were used except for the following changes to improve multiplexing: false priming threshold (0.8), primer dimer threshold (0.8), amplicon length variation (0.9), PCR primer $\mathrm{T}_{\mathrm{m}}$ variation (0.9), maximum pass iteration base (200). The design produced a single multiplex containing primer pairs and extension primers for 28 assays (Supplementary Material S1 and S2).

\section{MassARRAY genotyping}


High-throughput genotyping was performed using the Agena MassARRAY platform (Agena Bioscience, San Diego, CA, USA) to assign paternity of avocado seeds. Briefly, the extracted avocado seed DNA ( 2 uL; $\sim 10 \mathrm{ng} / \mathrm{ul}$ ) was amplified in $5 \mathrm{uL}$ multiplex PCR reactions containing $1 \mathrm{U}$ of Taq, $2.5 \mathrm{pmol}$ of each PCR primer, and $500 \mu \mathrm{M}$ of each dNTP (PCR Accessory and Enzyme Kit, Agena). Thermocycling was performed at $94^{\circ} \mathrm{C}$ for 4 min followed by 45 cycles of $94{ }^{\circ} \mathrm{C}$ for $20 \mathrm{~s}, 56^{\circ} \mathrm{C}$ for $30 \mathrm{~s}$, and $72{ }^{\circ} \mathrm{C}$ for 1 min, and a final extension at $72^{\circ} \mathrm{C}$ for $3 \mathrm{~min}$. Unincorporated dNTPs were deactivated using $0.5 \mathrm{U}$ of shrimp alkaline phosphatase $\left(37^{\circ} \mathrm{C}\right.$ for $4 \mathrm{~min}, 85^{\circ} \mathrm{C}$ for $5 \mathrm{~min}$ ). Primer extension was initiated by adding $1.3 \mathrm{U}$ of iPLEX GOLD, dideoxy nucleotide terminators and extension primers. The reaction conditions consisted of $95^{\circ} \mathrm{C}$ for $30 \mathrm{~s}, 40$ cycles of $95^{\circ} \mathrm{C}$ for $5 \mathrm{~s}$ plus five inner cycles of $52^{\circ} \mathrm{C}$ for $5 \mathrm{~s}$ and $80^{\circ} \mathrm{C}$ for $5 \mathrm{~s}$, and a final extension at $72{ }^{\circ} \mathrm{C}$ for $3 \mathrm{~min}$. A cation exchange resin was added to remove residual salt, and $7 \mathrm{~nL}$ of the purified primer extension product was loaded onto the matrix pad of a SpectroCHIP (Agena) using an RS1000 nanodispenser. The extension products were analysed by matrix assisted laser desorption ionization-time of flight mass spectrometry (MALDI-TOF MS) using a MassARRAY Analyser 4 (Agena). Mass spectra (4300 to 9000 Daltons) were interpreted with TYPER 4.0 software (Agena) to identify the alleles and to genotype the samples. A total of $98 \%$ of samples could be assigned by mass array.

We cross-validated the mass array results with pre-published microsatellite markers ${ }^{60,61}$. Details on the microsatellite markers and laboratory protocols are presented in Supplementary Material S2. The microsatellite markers could only assign $74 \%$ of the samples, but in those cases, $98 \%$ agreed with the mass array assignment.

\section{Statistical analyses}

We calculated the proportions of cross-pollinated and self-pollinated fruit per tree. We used two-way ANOVA to test whether distance from a cross-pollen source (measured as number of rows) and orchard affected the proportion of cross-pollinated and self-pollinated fruit. The interaction between distance and orchard was not significant. We used linear mixed models with tree number, transect and orchard as random effects to test whether distance from a cross-pollen source, as a fixed and categorical variable, affected fruit mass, flesh mass, seed mass and seed proportion. Flesh mass was calculated by subtracting seed mass from the fruit mass, and seed proportion was calculated as the amount of fruit mass that consisted of seed mass. Tukey's all-pair comparisons tests were performed when differences were detected.

We also used linear mixed models with tree number, transect and orchard as random effects to compare size and nutritional quality between self-pollinated fruit and fruit that were cross-pollinated by the predominant polliniser, Shepard. We compared (i) fruit mass, (ii) flesh mass, (iii) seed mass, (iv) seed proportion, ( $\mathrm{v}$ ) concentrations of each of 14 mineral nutrients, (vi) relative contributions of six fatty acids to the total fatty acid composition, (vii) relative contributions of saturated and unsaturated fatty acids to the total fatty acid composition, and (viii) ratio of unsaturated to saturated fatty acids. Data was logtransformed before analysis when necessary to achieve normal data distribution. Tukey's all-pair comparisons tests were performed when differences were detected. 
Statistical analyses were performed using $\mathrm{R}$ version 3.1.1 for Macintosh OS $\mathrm{X}^{62}$. Mixed models were performed with the package 'ImerTest' and 'multcomp' in $\mathrm{R}^{63}$.

\section{Declarations}

\section{Acknowledgements}

We thank Simpson Farms and Costa Avocado for assistance and access to their orchards. We thank Tarran Richards, Peter Brooks and Tsvakai Gama for field and laboratory advice and assistance. This work was funded by the Ruhr University Research School PLUS, which is funded by Germany's Excellence Initiative [DFG GSC 98/3], and project PH16001 of the Hort Frontiers Pollination Fund, part of the Hort Frontiers strategic partnership initiative developed by Hort Innovation, with co-investment from Griffith University, University of the Sunshine Coast, Plant \& Food Research Ltd and contributions from the Australian Government.

\section{Author contributions}

W.K., S.J.T. and S.M.O. conceived and designed the experiment and reviewed drafts of the paper. D.H. developed and wrote the section on the mass array method. W.K. collected the data, analysed the data, and wrote the first draft of the paper. All authors provided final approval for publication.

\section{Competing interests}

The authors declare no competing interests.

\section{Data availability}

Data used in analyses are uploaded as supplementary material.

\section{References}

1. Ashman, T.-L. et al. Pollen limitation of plant reproduction: ecological and evolutionary causes and consequences. Ecology 85, 2408-2421 (2004).

2. Ricketts, T. H. et al. Landscape effects on crop pollination services: are there general patterns? Ecol. Lett. 11, 499-515 (2008).

3. Rollin, O. \& Garibaldi, L. A. Impacts of honeybee density on crop yield: A meta-analysis. J. Appl. Ecol. 56, 1152-1163, doi:10.1111/1365-2664.13355 (2019).

4. Bennett, J. M. et al. Land use and pollinator dependency drives global patterns of pollen limitation in the Anthropocene. Nat. Commun. 11, 3999, doi:10.1038/s41467-020-17751-y (2020). 
5. Aizen, M. A. \& Harder, L. D. Expanding the limits of the pollen-limitation concept: effects of pollen quantity and quality. Ecology 88, 271-281 (2007).

6. Igic, B. \& Kohn, J. R. The distribution of plant mating systems: study bias against obligately outcrossing species. Evolution 60, 1098-1103 (2006).

7. Abrol, D. P. in Pollination Biology: Biodiversity and Conservation and Agricultural Production. Applied Pollination: Present Scenario 55-83 (Springer, 2012).

8. Frankel, R. \& Galun, E. Pollination mechanisms, reproduction and plant breeding. Vol. 2 (Springer Verlag, 1977).

9. Schneider, D., Goldway, M., Rotman, N., Adato, I. \& Stern, R. A. Cross-pollination improves 'Orri' mandarin fruit yield. Sci. Hortic. 122, 380-384 (2009).

10. Fattahi, R., Mohammadzedeh, M. \& Khadivi-Khub, A. Influence of different pollen sources on nut and kernel characteristics of hazelnut. Sci. Hortic. 173, 15-19 (2014).

11. Żurawicz, E., Studnicki, M., Kubik, J. \& Pruski, K. A careful choice of compatible pollinizers significantly improves the size of fruits in red raspberry (Rubus idaeus L.). Sci. Hortic. 235, 253-257 (2018).

12. Garibaldi, L. A. et al. Wild pollinators enhance fruit set of crops regardless of honey bee abundance. Science 339, 1608-1611, doi:10.1126/science.1230200 (2013).

13. Willcox, B. K., Aizen, M. A., Cunningham, S. A., Mayfield, M. M. \& Rader, R. Deconstructing pollinator community effectiveness. Curr. Opin. Insect. Sci. 21, 98-104, doi:https://doi.org/10.1016/j.cois.2017.05.012 (2017).

14. Richards, T. E. et al. Relationships between nut size, kernel quality, nutritional composition and levels of outcrossing in three macadamia cultivars. Plants 9, 228 (2020).

15. van Nocker, S. \& Gardiner, S. E. Breeding better cultivars, faster: applications of new technologies for the rapid deployment of superior horticultural tree crops. Hortic. Res. 1, 14022, doi:10.1038/hortres.2014.22 (2014).

16. Isaacs, R. \& Kirk, A. K. Pollination services provided to small and large highbush blueberry fields by wild and managed bees. J. Appl. Ecol. 47, 841-849 (2010).

17. Brittain, C., Kremen, C., Garber, A. \& Klein, A.-M. Pollination and plant resources change the nutritional quality of almonds for human health. PLOS ONE 9, e90082, doi:https://doi.org/10.1371/journal.pone.0090082 (2014).

18. Klatt, B. K. et al. Bee pollination improves crop quality, shelf life and commercial value. Proc. R. Soc. B 281, 20132440 (2014).

19. Jalali-Khanabadi, B.-A., Mozaffari-Khosravi, H. \& Parsaeyan, N. Effects of almond dietary supplementation on coronary heart disease lipid risk factors and serum lipid oxidation parameters in men with mild hyperlipidemia. J. Altern. Complement. Med. 16, 1279-1283 (2010).

20. Crane, J. et al. in The avocado: Botany, production and uses. Cultivars and rootstocks (eds B. Schaffer, B.N. Wolstenholme, \& A.W. Whiley) 200-233 (CABI, 2013). 
21. Duarte, P. F., Chaves, M. A., Borges, C. D. \& Mendonça, C. R. B. Avocado: characteristics, health benefits and uses. Cienc Rural 46, 747-754, doi:http://dx.doi.org/10.1590/0103-8478cr20141516 (2016).

22. Dreher, M. L. \& Davenport, A. J. Hass avocado composition and potential health effects. Crit. Rev. Food Sci. Nutr. 53, 738-750, doi:https://doi.org/10.1080/10408398.2011.556759 (2013).

23. Araújo, R. G., Rodriguez-Jasso, R. M., Ruiz, H. A., Pintado, M. M. E. \& Aguilar, C. N. Avocado byproducts: Nutritional and functional properties. Trends Food Sci. Technol. 80, 51-60, doi:https://doi.org/10.1016/j.tifs.2018.07.027 (2018).

24. Lerman-Garber, I., Ichazo-Cerro, S., Zamora-González, J., Cardoso-Saldaña, G. \& Posadas-Romero, C. Effect of a high-monounsaturated fat diet enriched with avocado in NIDDM patients. Diabetes Care 17, 311-315, doi:https://doi.org/10.2337/diacare.17.4.311 (1994).

25. López, L. R. et al. Monounsaturated fatty acid (avocado) rich diet for mild hypercholesterolemia. Arch. Med. Res. 27, 519-523 (1996).

26. Kris-Etherton, P. M. et al. High-monounsaturated fatty acid diets lower both plasma cholesterol and triacylglycerol concentrations. Am. J. Clin. Nutr. 70, 1009-1015 (1999).

27. Trueman, S. J., Richards, S., McConchie, C. A. \& Turnbull, C. G. N. Relationships between kernel oil content, fruit removal force and abscission in macadamia. Aust. J. Exp. Agric. 40, 859-866 (2000).

28. Stout, A. B. A study in cross-pollination of avocados in southern California. (New York Botanical Garden, 1923).

29. Salazar-García, S., Garner, L. C. \& Lovatt, C. J. in The avocado: Botany, production and uses. Reproductive Biology (eds B. Schaffer, B.N. Wolstenholme, \& A.W. Whiley) 118-167 (CABI, 2013).

30. Vithanage, V. The role of the European honeybee (Apis mellifera L.) in avocado pollination. $J$ Hortic Sci 65, 81-86, doi:10.1080/00221589.1990.11516033 (1990).

31. Perez-Balam, J. et al. The contribution of honey bees, flies and wasps to avocado (Persea americana) pollination in southern Mexico. J. Pollinat. Ecol. 8, 42-47 (2012).

32. Ying, Z., Davenport, T. L. R., Zhang, T., Schnell, R. J. \& Tondo, C. L. Selection of Highly Informative Microsatellite Markers to Identify Pollen Donors in@ Hass Avocado Orchards. Plant Mol. Biol. Rep. 27, 374-380 (2009).

33. Alcaraz, M. \& Hormaza, J. Influence of physical distance between cultivars on yield, outcrossing rate and selective fruit drop in avocado (Persea americana, Lauraceae). Ann. Appl. Biol. 158, 354-361 (2011).

34. Borrone, J. W. et al. Outcrossing in Florida avocados as measured using microsatellite markers. J. Am. Soc. Hortic. Sci. 133, 255-261 (2008).

35. Schnell, R. J. et al. Outcrossing between 'Bacon' Pollinizers and Adjacent 'Hass' Avocado Trees and the Description of Two New Lethal Mutants. HortScience 44, 1522, doi:10.21273/hortsci.44.6.1522 (2009). 
36. Degani, C., Goldring, A., Adato, I., El-Batsri, R. \& Gazit, S. Pollen Parent Effect on Outcrossing Rate, Yield, and Fruit Characteristics of 'Fuerte' Avocado. HortScience 25, 471, doi:10.21273/hortsci.25.4.471 (1990).

37. Sedgley, M. \& Annells, C. M. Flowering and fruit-set response to temperature in the avocado cultivar 'Hass'. Sci. Hortic. 14, 27-33, doi:https://doi.org/10.1016/0304-4238(81)90075-3 (1981).

38. Degani, C., El-Batsri, R. \& Gazit, S. Outcrossing rate, yield, and selective fruit abscission in'Ettinger' and 'Ardith' avocado plots. J. Am. Soc. Hortic. Sci. 122, 813-817 (1997).

39. Ying, Z. et al. Re-evaluation of the roles of honeybees and wind on pollination in avocado. J. Hortic. Sci. Biotech. 84, 255-260, doi:10.1080/14620316.2009.11512513 (2009).

40. Sapir, G. et al. Synergistic effects between bumblebees and honey bees in apple orchards increase cross pollination, seed number and fruit size. Sci. Hortic. 219, 107-117, doi:https://doi.org/10.1016/j.scienta.2017.03.010 (2017).

41. Stern, R., Eisikowitch, D. \& Dag, A. Sequential introduction of honeybee colonies and doubling their density increases cross-pollination, fruit-set and yield in 'Red Delicious' apple. J. Hortic. Sci. Biotech. 76, 17-23, doi:10.1080/14620316.2001.11511320 (2001).

42. Kämper, W., Trueman, S. J., Ogbourne, S. M. \& Wallace, H. M. Pollination services in macadamia depend on across-orchard transport of cross pollen. J. Appl. Ecol. (under revision).

43. Denney, J. O. Xenia includes metaxenia. HortScience 27, 722-728 (1992).

44. Robbertse, P. J., Coetzer, L. A., Johannsmeier, M. F., Köhne, J. S. \& Morudu, T. M. Hass Yield and Fruit Size as Influenced by Pollination and Pollen Donor-a Joint Progress Report. 63-67 (South African Avocado Growers' Association Yearbook 1996).

45. Araújo, E., Costa, M., Chaud-Netto, J. \& Fowler, H. G. Body size and flight distance in stingless bees (Hymenoptera: Meliponini): inference of flight range and possible ecological implications. Braz. J. Biol. 64, 563-568 (2004).

46. Kaiser, C. \& Wolstenholme, B. N. Aspects of delayed harvest of 'Hass' avocado (Persea americana Mill.) fruit in a cool subtropical climate. I. Fruit lipid and fatty acid accumulation. J Hortic Sci 69, 437-445, doi:10.1080/14620316.1994.11516473 (1994).

47. Smil, V. Phosphorus in the environment: natural flows and human interferences. Annu. Rev. Environ. Resour. 25, 53-88, doi:10.1146/annurev.energy.25.1.53 (2000).

48. Hopkirk, G., White, A., Beever, D. J. \& Forbes, S. K. Influence of postharvest temperatures and the rate of fruit ripening on internal postharvest rots and disorders of New Zealand 'Hass' avocado fruit. New Zeal. J. Crop. Hort. 22, 305-311, doi:https://doi.org/10.1080/01140671.1994.9513839 (1994).

49. Meir, S. et al. Prolonged storage of 'Hass' avocado fruit using modified atmosphere packaging. Postharvest Biol. Technol. 12, 51-60, doi:https://doi.org/10.1016/S0925-5214(97)00038-0 (1997).

50. Flitsanov, U., Mizrach, A., Liberzon, A., Akerman, M. \& Zauberman, G. Measurement of avocado softening at various temperatures using ultrasound. Postharvest Biol. Technol. 20, 279-286 (2000). 
51. Hofman, P. J., Bower, J. \& Woolf, A. in The avocado: botany, production and uses. Harvesting, packing, postharvest technology, transport and processing (eds B. Schaffer, B.N. Wolstenholme, \& A.W. Whiley) 489-540 (CABI, 2013).

52. McGeehan, S. L. \& Naylor, D. V. Automated instrumental analysis of carbon and nitrogen in plant and soil samples. Commun. Soil Sci. Plant Anal. 19, 493-505, doi:https://doi.org/10.1080/00103628809367953 (1988).

53. Rayment, G. E. \& Higginson, F. R. Australian laboratory handbook of soil and water chemical methods. (Inkata, 1992).

54. Munter, R. C. \& Grande, R. A. in Developments in Atomic Plasma Spectrochemical Analysis. Plant tissue and soil extract analysis by ICP-atomic emission spectrometry (ed RM Byrnes) 653-672 (Heyden, 1981).

55. Martinie, G. D. \& Schilt, A. A. Wet oxidation efficiencies of perchloric acid mixtures for various organic substances and the identities of residual matter. Anal. Chem. 48, 70-74, doi:https://doi.org/10.1021/ac60365a032 (1976).

56. Bai, S. H. et al. Nutritional quality of almond, canarium, cashew and pistachio and their oil photooxidative stability. J. Food Sci. Technol. 56, 792-798, doi:https://doi.org/10.1007/s13197-0183539-6 (2019).

57. Ivanova, N. V., Fazekas, A. J. \& Hebert, P. D. N. Semi-automated, membrane-based protocol for DNA isolation from plants. Plant Mol. Biol. Rep. 26, 186-198 (2008).

58. Kämper, W., Cooke, J., Trueman, S. J. \& Ogbourne, S. M. Detection of single nucleotide polymorphisms (SNPs) in avocado cultivars, Persea americana (Lauraceae). Applications in Plant Sciences (submitted).

59. Jordon-Thaden, I. E. et al. A basic ddRADseq two-enzyme protocol performs well with herbarium and silica-dried tissues across four genera. Applications in plant sciences 8, e11344-e11344, doi:10.1002/aps3.11344 (2020).

60. Sharon, D. et al. An integrated genetic linkage map of avocado. Theor. Appl. Genet. 95, 911-921 (1997).

61. Borrone, J. W., Schnell, R. J., Violi, H. A. \& Ploetz, R. C. Seventy microsatellite markers from Persea americana Miller (avocado) expressed sequence tags. Mol. Ecol. Resour. 7, 439-444 (2007).

62. R Core Team. R: A language and environment for statistical computing. R Foundation for Statistical Computing (2015).

63. Kuznetsova, A., Brockhoff, P. B. \& Christensen, R. H. ImerTest package: tests in linear mixed effects models. J. Stat. Softw. 82, 1-26 (2017).

\section{Figures}




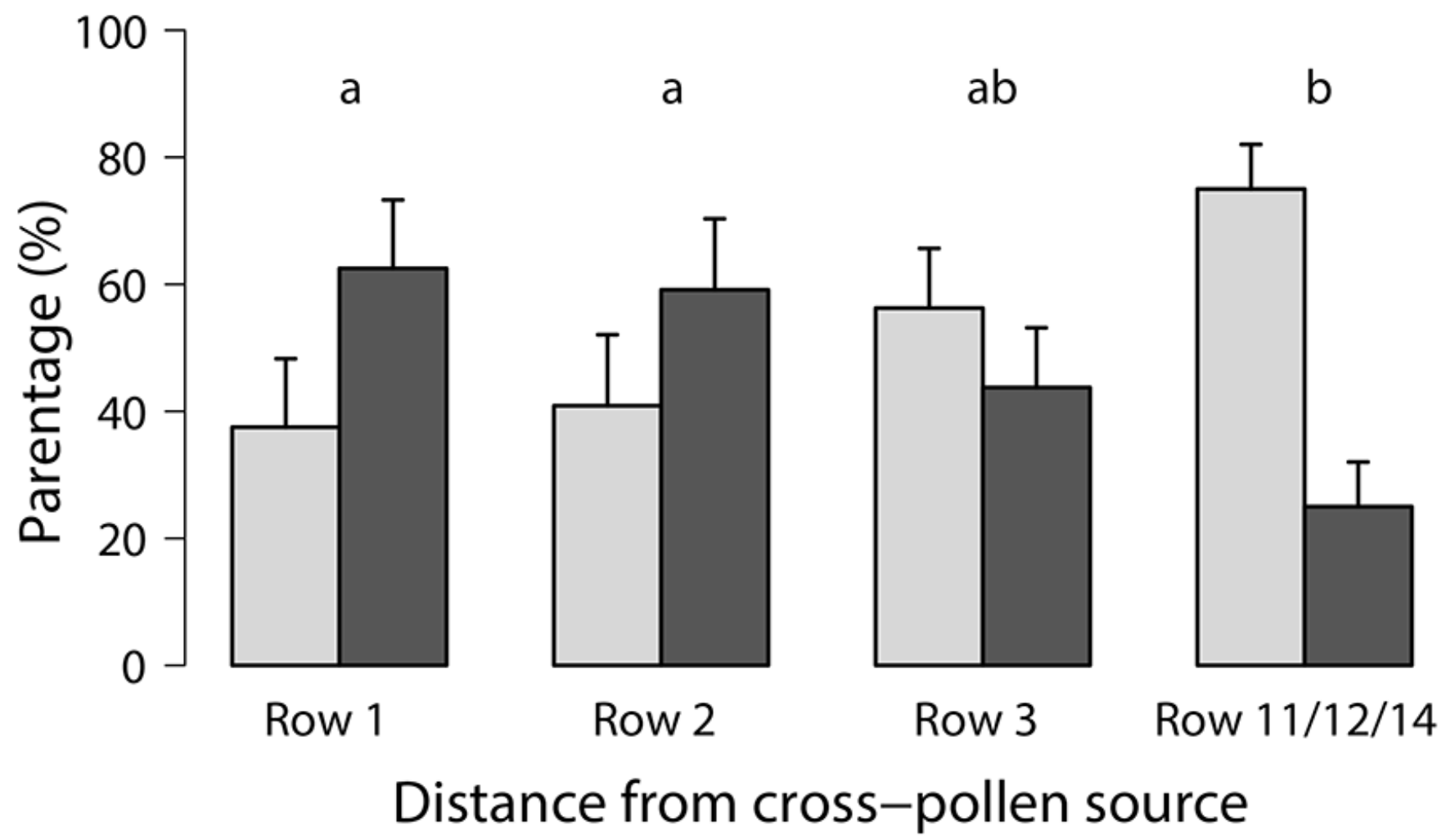

Self-pollinated fruit $\square$ Cross-pollinated fruit

Figure 1

Percentage of cross-pollinated and self-pollinated Hass avocado fruits at different numbers of rows from a cross-pollen source. Fruits were sampled along transects starting at trees adjacent to another cultivar (Row 1) and ending in the middle row of the Hass block (Row 11, 12 or 14). Means (+ SE) for crossparentage and self-parentage with different letters are significantly different (two-way ANOVA and Tukey's HSD; $\mathrm{P}<0.05 ; \mathrm{n}=8$ ). 


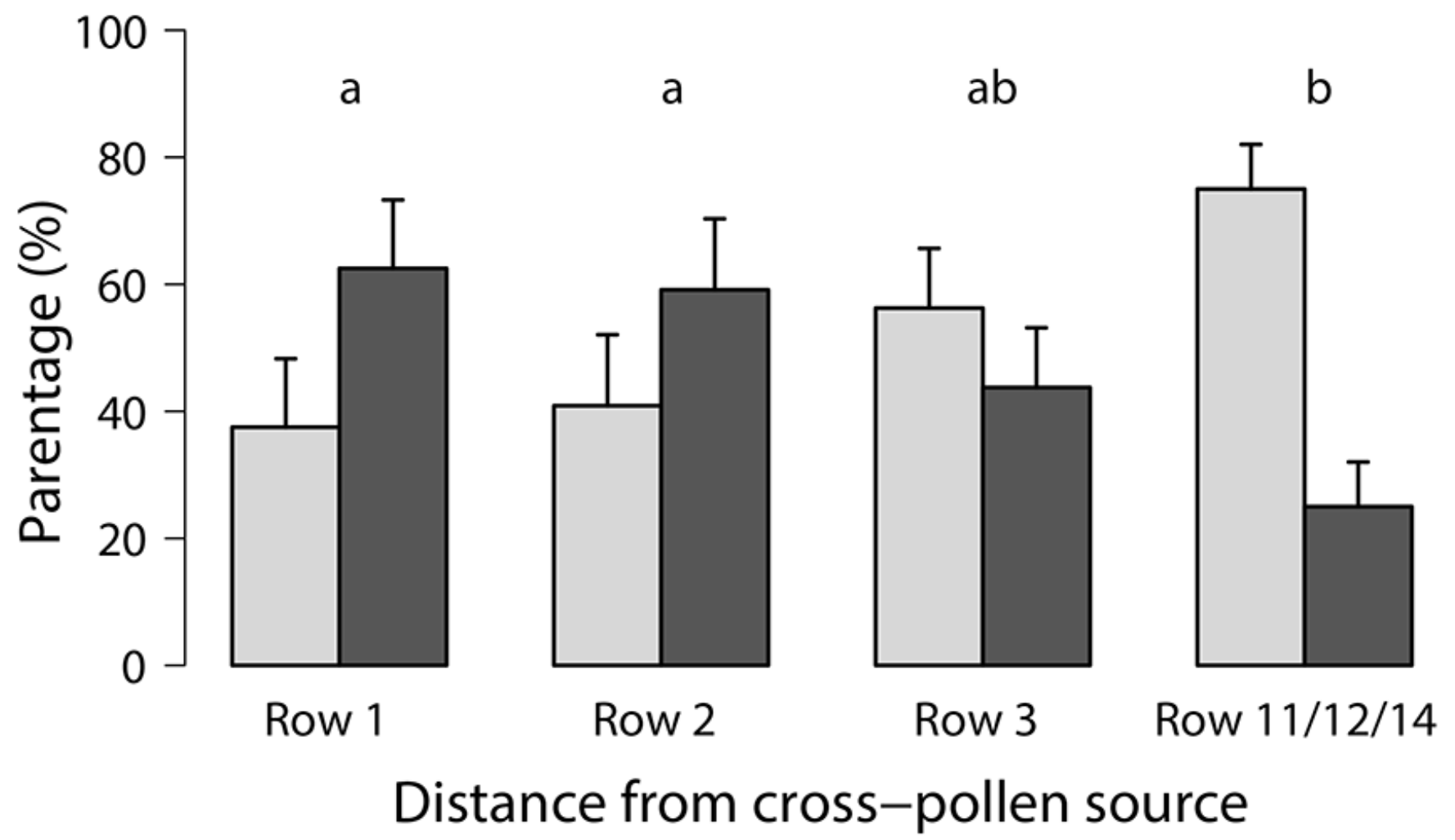

\section{Self-pollinated fruit $\quad \square$ Cross-pollinated fruit}

\section{Figure 1}

Percentage of cross-pollinated and self-pollinated Hass avocado fruits at different numbers of rows from a cross-pollen source. Fruits were sampled along transects starting at trees adjacent to another cultivar (Row 1) and ending in the middle row of the Hass block (Row 11, 12 or 14). Means (+ SE) for crossparentage and self-parentage with different letters are significantly different (two-way ANOVA and Tukey's HSD; $\mathrm{P}<0.05 ; \mathrm{n}=8$ ).

\section{Supplementary Files}

This is a list of supplementary files associated with this preprint. Click to download.

- SupplementaryMaterialS1.xlsx

- SupplementaryMaterialS1.xIsx

- Supplementarymaterial2updated.docx

- Supplementarymaterial2updated.docx

- DataFruitqualityandpaternityplain.xlsx

- DataFruitqualityandpaternityplain.xlsx

- DataMicrosatellitegenotypes.xlsx 
- DataMicrosatellitegenotypes.xIsx 